\title{
Optimization Design Method for Photovoltaic and Energy Storage Grid-Connected Microgrid Considering Power Optimization of Distribution Network
}

\author{
Yongfu Liu ${ }^{1}$, Jun Wang ${ }^{2, *}$, Bart $\mathrm{Di}^{3}$ and Mingjian Zhang ${ }^{4}$ \\ ${ }^{1}$ College of Information Science and Technology, Hebei Agricultural University, Baoding 071000, China \\ ${ }^{2}$ College of Information and Electric Engineering, Shenyang Agricultural University, Shenyang 110866, China \\ ${ }^{3}$ Emanden Technical Solutions Pty Ltd, Adelaide, Australia \\ ${ }^{4}$ Maintenance Company of Liaoning, State Grid, Shenyang 110006, China
}

Received 6 December 2020; Accepted 27 February 2021

\begin{abstract}
Microgrid is a novel power grid that combines various distributed generation, energy storage systems, and loads. It complements the distribution network to realize energy saving and emission reduction. To optimize the power of the microgrid that is connected to the distribution network and maximize the utilization rate of renewable energy, this study proposed a design method, a work mode, and a control strategy for photovoltaic (PV) and energy storage microgrid. A PV and energy storage microgrid structure was designed on the basis of the organic whole of a grid-connected microgrid and distribution network. According to the maximum and minimum load operations of the system, a mathematical model for determining micro-power capacity was established. Moreover, a mathematical model of coordinated control of microgrid system was established by controlling the active and reactive microgrid power separately. The membership function of control variables was proposed, and the fuzzy set of control variables and the fuzzy control decision table were established to determine the working mode of active micro-source. Taking the actual typical daily load characteristic curves in summer and winter as examples, the effectiveness and superiority of the proposed optimization design method for microgrid were verified. Results demonstrate that the work mode and control strategy of the microgrid system cannot only smoothen the active power at the head end of $0.4 \mathrm{kV}$ distribution line but also optimize the reactive power of the system. The power factor of $0.4 \mathrm{kV}$ distribution line meets the requirements. The study can be used as reference for designing a microgrid that is connected to the distribution network.
\end{abstract}

Keywords: Microgrid, Distribution network, Power optimization, Fuzzy control strategy

\section{Introduction}

To integrate the advantages of distributed generation (DG) and weaken its negative influence on power grid, Lasseter et al. proposed the concept of microgrid [1]. Microgrid provides an effective technical approach for the grid connection of renewable energy with high permeability by combining renewable energy power supply system, controllable power supply, energy storage system (ESS), and load organically [2][3]. ESS is an important part of microgrid because it can stabilize the fluctuation of intermittent power supplies, such as wind power generation and photovoltaic (PV) power generation, and has the function of voltage regulation and peak clipping [4][5]. The safe and economical operation and stable system regulation of microgrid can improve energy utilization rate and save power generation cost. Meanwhile, it provides important support for the safe operation of the power grid [6].

As an organic whole, grid-connected microgrid and distribution network realize energy exchange through the point of common coupling (PCC). Based on microgrid, the distribution network can freely cope with different operating conditions and manage energy exchange between microgrid and distribution network efficiently to realize the maximum utilization of DG [7]. As an organic integration of DGs and loads, an independent microgrid can realize more reasonable, economical, and effective energy supply in remote areas [8]. The optimal allocation of microgrid capacity directly influences key technical indicators, such as the cascade comprehensive utilization efficiency of energy, power supply reliability, and power quality. Therefore, it is the primary problem to be solved in the microgrid planning and design stages.

Microgrid optimization design has become an important microgrid key technology. Scholars have carried out numerous studies and presented a series of operation control strategies and optimization planning methods [9][10][11]. However, the design of the PV and energy storage microgrid with fuzzy control based on mathematical model is scare. Therefore, based on the work mode of active micro source, fuzzy control decision making by establishing mathematical model is an important study direction.

This study establishes a microgrid to study the method for determining microgrid capacity to realize system power optimization based on the organic whole of grid-connected microgrid and distribution network, considering the change in the load of the distribution network. The work mode and control strategy of the microgrid are also investigated. This study can provide reference for the optimization design of a microgrid that is connected to the distribution network. 


\section{State of the Art}

At present, scholars have carried out many studies on microgrids that are connected to distribution networks. Liu [11] established a two-layer optimization planning and design model suitable for grid-connected microgrid system and independent microgrid system. Although the scheduling optimization among micro sources was realized, the influence of energy storage module on the scheduling optimization of microgrids was not considered. Dou [12] developed a method for optimizing the capacity allocation of grid-connected wind and solar storage microgrid and established an optimization model for the capacity allocation of wind, PV, and energy storage. An improved genetic algorithm was used for optimization calculation. However, the study failed to improve the economic efficiency and environmental protection of the system planning scheme by using demand response. Lu [13] used adaptive grid multiobjective particle swarm optimization algorithm to analyze the multi-objective optimization design of wind-PV hybrid system with hybrid energy storage. The load demand was considered; however, the importance of the transmission channel was neglected. Mansour-Lakouraj [14] proposed a new two-stage risk constraint stochastic framework, which can realize the optimal scheduling of microgrids in normal and emergency situations but does not consider power optimization. Elmouatamid [15] proposed a model to predict the power generation and consumption of microgrid system and the state of charge (SOC) of battery. The model is controlled by predictive and real-time values to balance the demand/response but does not consider the efficient utilization of energy. Nassourou [16] proposed an economic prediction model that considers $\mathrm{PV}$, wind power, water power, and energy storage equipment, which can carry out energy scheduling effectively but neglects the comprehensive utilization of distributed energy. Ko [17] proposed a novel power quality control scheme for microgrid based on voltage and frequency without considering the effective utilization of DG. Sachs [18] established a multi-objective optimal allocation model from the perspectives of economical efficiency and environmental protection, thereby realizing the optimal capacity allocation of each component in the microgrid and the layout planning of power electronic equipment. However, the optimization of power was neglected. According to Omran [19], in normal power fluctuation range, the PV load shedding operation is more economical than adding energy storage equipment. However, obtaining the maximum power point (MPP) is difficult. Pappu [20] established a general model of two-stage PV grid-connected system with frequency response capability that was suitable for the study of power system. The output reference voltage was set according to the open circuit voltage, and the PV works on the left side of the voltage that corresponds to MPP to realize load shedding control. Nanou [21] used the quadratic function to estimate the maximum power and set the PV output power to $\mathrm{k}(\mathrm{k}<1)$ times of the maximum power to realize load shedding control. Wu [22] solved the economical scheduling of microgrid based on the mixed integer programming method. Although the active power balance and control in microgrid were considered, the reactive power control was ignored. Guo [23] established an energy optimization model suitable for independent microgrid by considering the operating characteristics of diesel generator set and DSM load comprehensively; however, the power optimization problem was not considered. Ding [24] and Saif [25] introduced the capacity optimization allocation for independent microgrid but neglected power optimization.

The aforementioned studies focus on optimizing the economical efficiency, reliability, and power capacity of power grid. However, the design of PV and energy storage microgrid aiming at optimizing the power of distribution network and maximizing renewable energy is scarce. Based on the grid-connected microgrid and distribution network as a whole, this study designed a PV and energy storage gridconnected distribution network structure. According to the load operation situation, mathematical models that determine the capacity and coordination control of microgrid systems were established. For the operating mode of active microsources, the membership function of control variables and fuzzy control strategy were proposed. Taking the actual typical daily load characteristic curves in summer and winter as examples, the effectiveness and superiority of the proposed optimization design method for microgrid were verified.

The remainder of this study is organized as follows. Section 3 establishes the mathematical model of determination capacity and coordination control of micropower and proposes the membership functions of control variables and fuzzy control strategies for the operating mode of active micro-source. Section 4 verifies the effectiveness and superiority of the proposed micro-grid optimization design method based on an example. Finally, Section 5 summarizes this study and draws the conclusions.

\section{Methodology}

\subsection{Analysis of characteristics of microgrid networking and micro power supply}

\subsubsection{Microgrid structure}

The full utilization of resources is an important part of the design principle of a microgrid structure; moreover, the maximization of resource utilization and the complementarity of energy should be considered in the design and planning of microgrid structure [26]. Therefore, considering the characteristics of local load and energy, this study used PV cells, energy storage cells, and static var generator (SVG) to design a microgrid (Fig. 1). The power factors of PV and energy storage cells are set to 1 [27]. PV and energy storage cells are active micro-source, whereas SVG is a reactive micro-source. In the microgrid system, each DG is regulated by power electronic devices, connected to the microgrid $\mathrm{AC}$ bus, and then connected to the distribution network with the static switches and transformers at the PCC.

\subsubsection{Characteristics of PV power generation system}

According to [28], a simulation system was established on the basis of a MATLAB simulation platform. The P-V characteristic curves of the PV cells under different illumination intensities $\left(T_{b}=25{ }^{\circ} \mathrm{C}\right.$ is unchanged) are shown in Fig. 2, and the P-V characteristic curves of the PV cells at different temperatures ( $S_{b}=1000 \mathrm{~W} / \mathrm{m}^{2}$ is unchanged) are presented in Fig. 3.

The characteristic curves in Figs. 2 and 3 show that PV cells have obvious nonlinear volt-ampere characteristics. PV cell is neither a constant current source nor a constant voltage source. As a nonlinear DC power supply, it cannot provide large power for load. In Fig. 2, short-circuit current 
$I_{s c}$ increases obviously with the illumination intensity; however, the open-circuit voltage does not increase obviously. Meanwhile, the output power $P$ first increases and then decreases and then obtains a MPP. As the illumination intensity increases, the maximum output power increases in proportion. As shown in Fig. 3, with the increase in temperature, the short-circuit current $I_{s c}$ increases slightly, but the open-circuit voltage decreases. Similarly, the output power $P$ first increases and then decreases, and there is a MPP. The temperature rises, but the maximum output power does not change obviously.

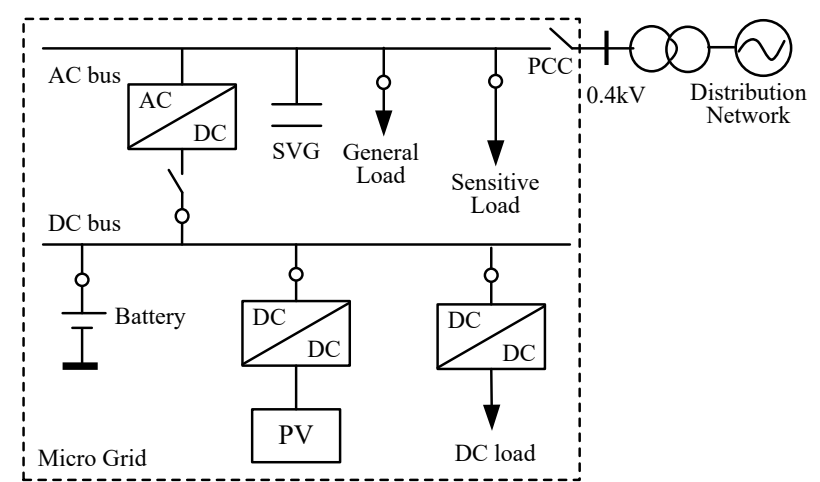

Fig. 1. Structural diagram of microgrid composed of PV and energy storage battery

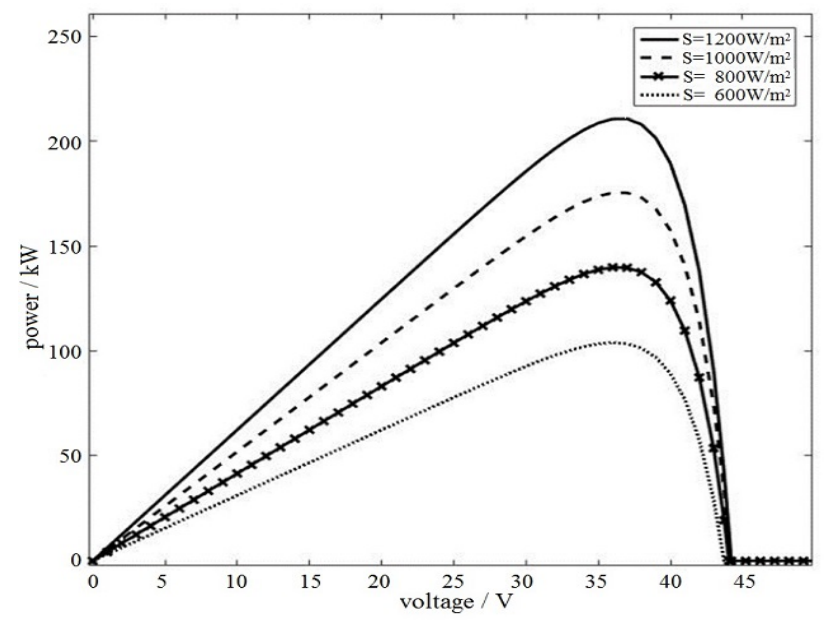

Fig. 2. P-V characteristic curve of PV battery under different illumination intensities

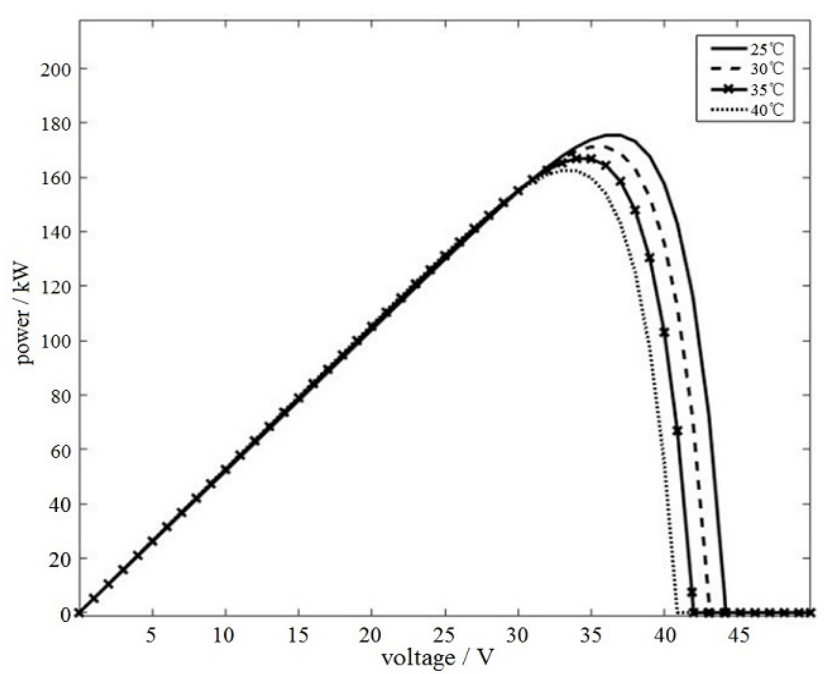

Fig. 3. P-V characteristic curve of PV battery under different temperatures

\subsubsection{Characteristics of battery ESS}

ESS is an important part of the microgrid system. The power distribution in the microgrid can be adjusted through the rapid charging and discharging of electric energy, and the power fluctuation of intermittent micro power supply can be suppressed. In this way, the power quality at the user end is enhanced, the ability of the microgrid to cope with large grid emergencies is strengthened, and the stability of the microgrid operation is improved. Therefore, studying the application of ESS in microgrid is necessary. If the total battery capacity is $Q$, then the state of charge (SOC) is expressed as follows:

$$
\operatorname{SOC}(t)=\frac{Q_{r}(t)}{Q} \times 100 \%
$$

where $Q_{r}(t)$ is the remaining charge in the battery.

$i(t)$ is the internal current of the battery, which is positive when charging. $i(t)$ is determined by the voltage and load at both ends of the battery. When the total charge of battery is constant, $S O C$ varies with the current. In practice, the $S O C$ of the battery at $t$, which is calculated according to Formula (2).

$$
\operatorname{SOC}(t)=S O C_{i n i t}+\int\left(\frac{i(t)}{Q}\right) d t
$$

where $S O C_{\text {init }}$ is the initial value of $S O C$ of the battery.

According to Formula (2), when the total charge of battery and $S O C_{\text {init }}$ are constant, SOC shows a linear change relationship with the charging-discharging current. When the battery is charged, the battery SOC increases. When the battery is discharged, the battery $S O C$ decreases. As the absolute value of the charging-discharging current increases the battery $S O C$ increases, and vice versa.

\subsection{Mathematical model for determining the capacity of micro power supply}

The diagram of a microgrid that is connected to the power grid shown is presented in Fig. 4. According to the maximum and minimum load operation conditions of the system, the mathematical model for determining the capacity of the micro power supply is established to optimize the power of the system.

The maximum active and reactive power of $0.4 \mathrm{kV}$ distribution line load in Fig. 4 are $P_{\max }$ and $Q_{\max }$. The minimum active power of the load is $P_{\min }$. The active power at the head end of $0.4 \mathrm{kV}$ distribution line is $P_{0}$, and the reactive power is $Q_{0}$. The maximum power of the PV cell is $P_{P V . N}$. The maximum power of the storage battery is $P_{B E S S . N}$. The reactive power compensation is $Q_{S V G . N}$. The maximum and minimum active power of microgrid load are $P_{\text {Lmax }}$ and $P_{\text {Lmin }}$ respectively. The maximum reactive power of the microgrid load is $Q_{\text {Lmax }}$.

When the $0.4 \mathrm{kV}$ distribution line operates at the maximum load, the microgrid is taken as the power source connected to the distribution network. The power balance equation of the microgrid system shown in Fig. 4 is expressed as: 
$k_{P V . \max } P_{P V . N}+k_{B E S S \text { max }} P_{B E S S . N}-P_{L \max }=k_{P 1 . \max } P_{\max }$

$Q_{S V G . N}-Q_{L \max }=k_{Q . \max } Q_{\max }$

where $k_{P V \text {.max }}$ and $k_{B E S S \text { max }}$ are the utilization rates of the PV cell and the storage battery at the maximum load, respectively; $k_{P V \text {.max }} \in(0,1)$ and $k_{B E S S \text { max }} \in(0,1) ;$ and $k_{P 1 \text { max }}$ and $k_{Q \text {.max }}$ are the active and reactive load coefficients at maximum load, and $k_{P 1 . \max }$ and $k_{\text {Q.max }}$ are in the range of 0 to 1.

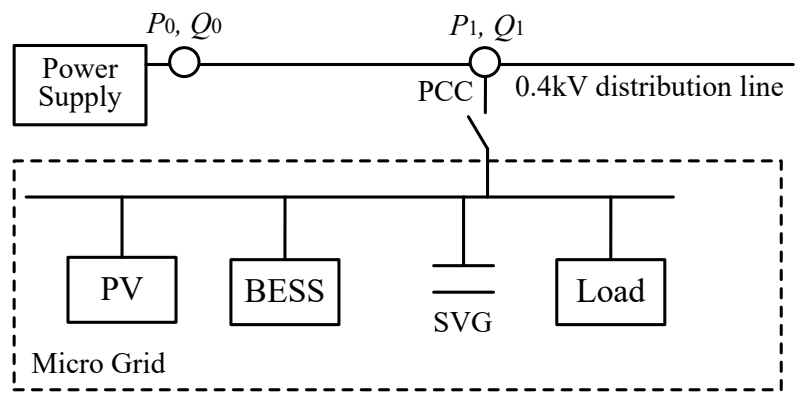

Fig. 4. Schematic diagram of microgrid access to the power grid

When the $0.4 \mathrm{kV}$ distribution line operates at the minimum load, the microgrid becomes the active load connected to the distribution network. The power balance equation of the system in Fig. 4 is expressed as:

$-k_{P V . \text { min }} P_{P V . N}+k_{B E S S . \text { min }} P_{B E S S . N}+P_{\text {Lmin }}=k_{P 1 . \text { min }} P_{\text {max }}$

where $k_{P V \text {.min }}$ and $k_{B E S S \text {.min }}$ are the utilization rates of PV cells and batteries at the minimum load, respectively; $k_{P V \text {.min }} \in[0,0.5]$ and $k_{B E S S \text {.min }} \in(0,1) ; k_{P 1 \text {.min }}$ is the active load factor at the minimum load; and $k_{P 1 \text { min }}$ is in the range of 0 to 1.

\subsection{Design of microgrid work mode and control strategy}

\subsubsection{Mathematical model for coordination control of} microgrid system

In the microgrid, the active and reactive powers are controlled separately to ensure the balance between the active and reactive power. The active power at the head end of the $0.4 \mathrm{kV}$ distribution line is smoothed, and the reactive power of the system is optimized. The power factor of 0.4 $\mathrm{kV}$ distribution line meets the requirements. Based on the maximum utilization rate of the output power of the PV cells, the mathematical model for the coordination control of the microgrid system is expressed as follows:

$$
\left\{\begin{array}{l}
S O C_{\text {min }} \leq S O C(t) \leq S O C_{\text {max }} \\
\left(P_{\text {min }}+k_{P l . m i n} P_{\text {max }}\right) \leq P_{0} \leq\left(1-k_{P 1 . \text { max }}\right) P_{\max } \\
0.97 \leq \cos \varphi \leq 1
\end{array}\right.
$$

where $S O C_{\max }$ and $S O C_{\min }$ are the upper and lower limits of the state of charge at time $t \operatorname{SOC}(t)$ of the ESS, which are $80 \%$ and $20 \%$ respectively; and $\cos \varphi$ is the power factor of the first section of the line.
3.3.2 Work modes and fuzzy control strategy of active micro source

(1) Work modes of active micro source

The work modes of active micro sources of the microgrid in different periods of time are shown in Table 1, which are represented by the corresponding symbols.

Table 1. Work modes of active micro power source

\begin{tabular}{l|l|l}
\hline \multicolumn{2}{l|}{ Work mode } & \multicolumn{2}{l}{ Microsource operation state } \\
\hline Name & Symbol & \\
\hline Mode 1 & M1 & $\begin{array}{l}\text { PV cell generates electricity, and the } \\
\text { battery is charged. }\end{array}$ \\
Mode 2 & M2 & $\begin{array}{l}\text { PV cell generates electricity, and the } \\
\text { battery is discharged } \\
\text { PV cell does not generate electricity, and } \\
\text { the battery is charged } \\
\text { PV cells do not generate electricity, and the } \\
\text { battery is discharged }\end{array}$ \\
Mode 4 & M3 & M4
\end{tabular}

(2) Fuzzy control strategy of active micro source

1) Determination of membership function

The membership function $\lambda$ of active load $P$ is as follows:

$\lambda=\left(P-P_{\min }\right) /\left(P_{\max }-P_{\min }\right)$

The membership function $\beta$ of output active power of $\mathrm{PV}$ cell is as below:

$\beta=P_{P V} / P_{P V . N}$

In this study, the triangular membership function is used to divide $\lambda$ into four fuzzy sets: zero (ZO), positive small (PS), positive median (PM) and positive big (PB), as shown in Fig.5 (a). $\beta$ and SOC of energy storage battery are divided into five fuzzy sets: zero (ZO), relative small (RS), positive small (PS), positive median (PM), and positive big (PB), as shown in Fig. (b) and (c).

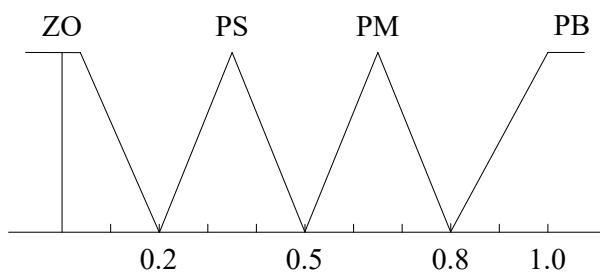

(a) Membership function $\lambda$ of active load

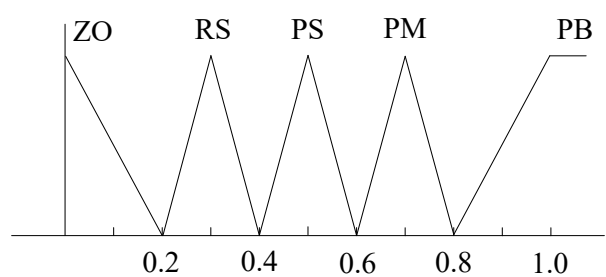

(b) Membership function of energy storage battery SOC

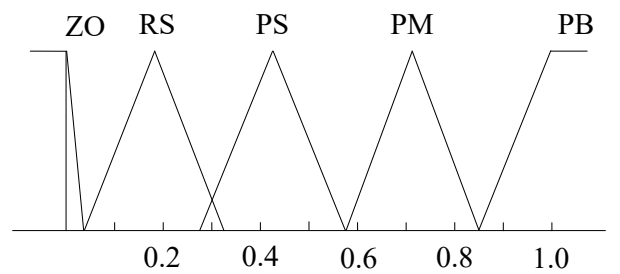

(c) Membership function $\beta$ of PV cell

Fig. 5. Membership function 
2) Determination of fuzzy control decision

The control variable of fuzzy control decision is $\lambda, \beta$, and SOC (Table 2). The fuzzy control strategy and the work mode of active micro source are determined according to Fig. 5.

Table 2. Fuzzy control strategy

\begin{tabular}{|c|c|c|c|}
\hline \multirow{2}{*}{$\begin{array}{c}\text { Operation } \\
\text { mode }\end{array}$} & \multicolumn{3}{|c|}{ Control variable } \\
\hline & $\operatorname{Load} \lambda$ & PV $\beta$ & SOC \\
\hline \multirow{6}{*}{ M1 } & & PB & $\mathrm{ZO}$ or $\mathrm{RS}$ or $\mathrm{PS}$ \\
\hline & PB & PM & $\mathrm{ZO}$ or RS or PS \\
\hline & PM & PM & $\mathrm{ZO}$ or RS or PS \\
\hline & & & 70 r RS or PS \\
\hline & PS & $\mathrm{PM}$ or $\mathrm{PB}$ & or PM (non-PB) \\
\hline & $\mathrm{ZO}$ & $\begin{array}{l}\text { RS or PS or PM } \\
\text { or } \mathrm{PB}(\text { non- } \mathrm{ZO})\end{array}$ & $\begin{array}{l}\mathrm{ZO} \text { or } \mathrm{RS} \text { or } \mathrm{PS} \\
\text { or } \mathrm{PM} \text { (non-PB) }\end{array}$ \\
\hline \multirow{3}{*}{ M2 } & PS or PM & $\mathrm{RS}$ & $\mathrm{PM}$ or $\mathrm{PB}$ \\
\hline & PM & PS & PB \\
\hline & PB & RS or PS & $\begin{array}{c}\text { RS or PS or PM } \\
\text { or } \mathrm{PB}\end{array}$ \\
\hline M3 & $\mathrm{ZO}$ or PS & $\mathrm{ZO}$ & $\begin{array}{c}\mathrm{ZO} \text { or } \mathrm{RS} \text { or } \mathrm{PS} \\
\text { or } \mathrm{PM}\end{array}$ \\
\hline \multirow[b]{2}{*}{ M4 } & PM & $\mathrm{ZO}$ & PS or $\mathrm{PM}$ or $\mathrm{PB}$ \\
\hline & PB & $\mathrm{ZO}$ & $\begin{array}{c}\mathrm{RS} \text { or } \mathrm{PS} \text { or } \mathrm{PM} \\
\text { or } \mathrm{PB}\end{array}$ \\
\hline
\end{tabular}

\section{Result Analysis and Discussion}

\subsection{Analysis of typical daily load}

The typical daily load characteristic curves of the $0.4 \mathrm{kV}$ distribution line in summer and winter are presented in Fig. 6. The active power $P_{0}$ at the head end of the line is shown in Fig. 6 (a), and the reactive power $Q_{0}$ at the head end of the line is presented in Fig. 6 (b). Typical daily load characteristic curves of the microgrid in summer and winter are shown in Fig. 7.

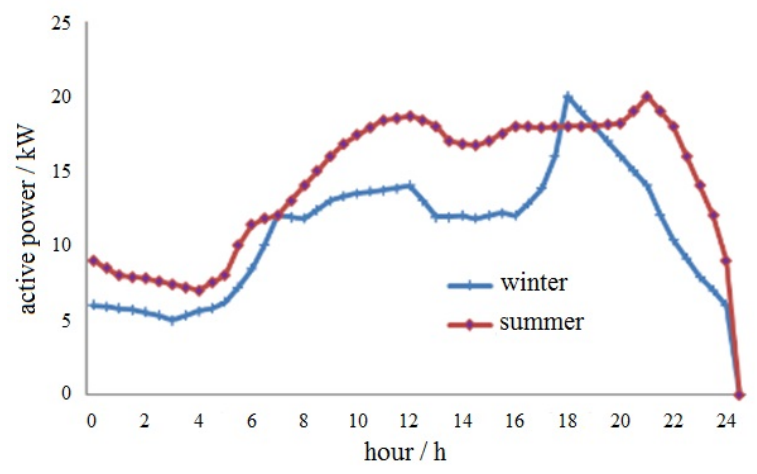

(a) Active load characteristic curve

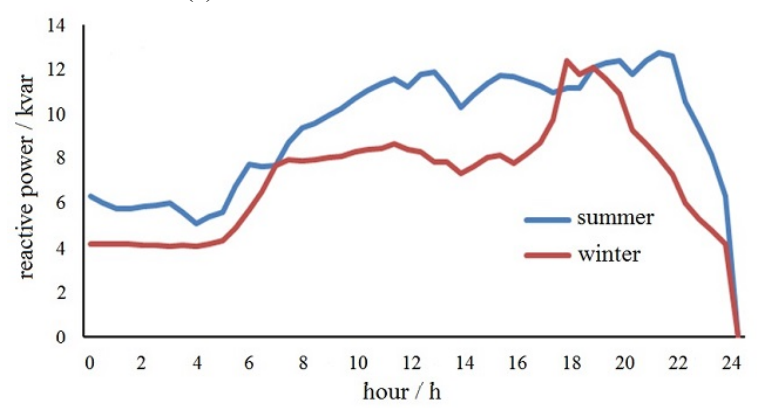

(b) Reactive load characteristic curve

Fig. 6. Load characteristic curve of $0.4 \mathrm{kV}$ distribution line

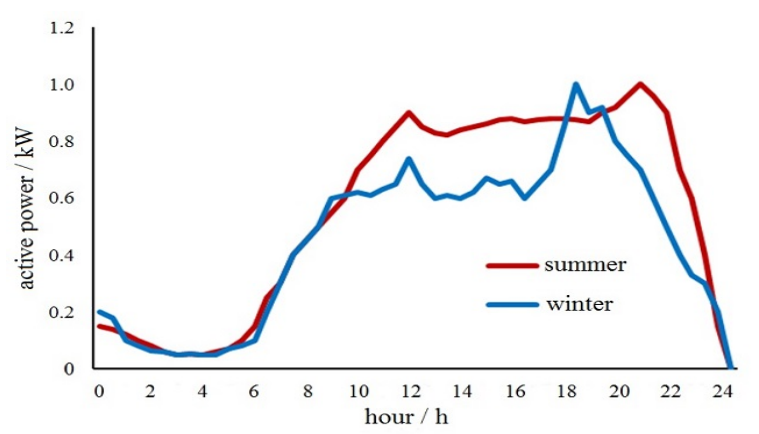

(a) Active load characteristic curve

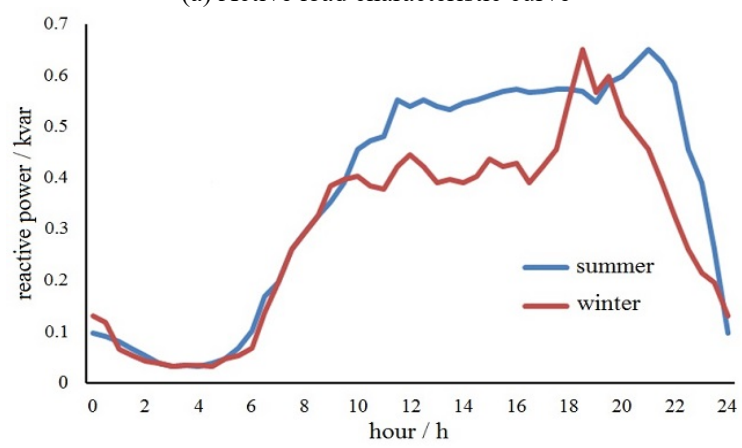

(b) Reactive load characteristic curve

Fig. 7. Power characteristic curve of microgrid load

The minimum active load $P_{\min }$ and maximum active load $P_{\max }$ of $0.4 \mathrm{kV}$ distribution line in Fig. 6 are $5 \mathrm{~kW}$ and 20 $\mathrm{kW}$, respectively. The maximum value $Q_{\max }$ of reactive power $Q_{0}$ is 50 kvar. The minimum load $P_{\text {Lmin }}$ of the microgrid is $50 \mathrm{~W}$, the maximum load power $P_{L \max }$ is $1 \mathrm{~kW}$, and the reactive power $Q_{L}$ is 0.1 kvar.

\subsection{Determination of capacity of micro power supply}

In this study, $k_{P V \text {.max }}$ is $0.6, k_{P V \text {.min }}$ is $0, k_{B E S S \text {.min }}$ is 0.2 , $k_{B E S S \text { max }}$ is $0.8, k_{P 1 \text { min }}$ is $0.3, k_{P 1 \text { max }}$ is 0.45 , and $k_{Q 1 . \text { max }}$ is 0.45 .

According to Formulas (3) to (5), the maximum power $P_{P V . N}$ of the PV cell is $10 \mathrm{~kW}$, and the maximum power $P_{B E S S . N}$ of the battery is $20 \mathrm{~A} \cdot \mathrm{h}$. The reactive power compensation $Q_{S V G . N}$ is 22.6 kvar.

\subsection{Implementation of microgrid control strategy}

The actual typical solar PV power characteristic curves in summer and winter are shown in Fig. 8. According to Figs. 6 and 7 , after the microgrid is connected to the $0.4 \mathrm{kV}$ distribution line, the work modes in different periods are shown in Table 3.

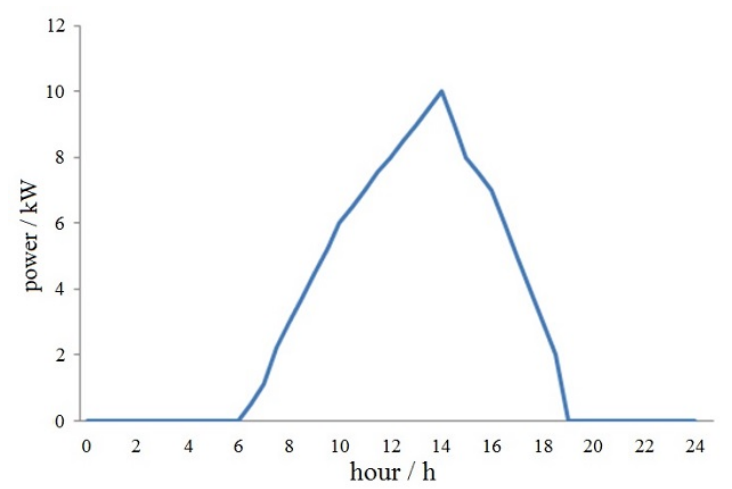

(a) Power characteristic curve of PV power generation in summer 


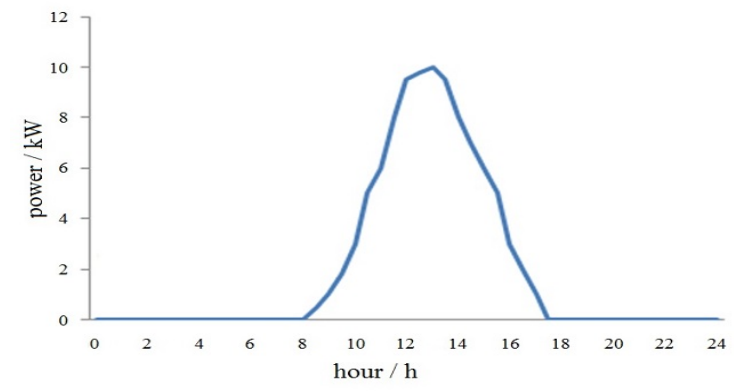

(b) Power characteristic curve of PV power generation in winter Fig. 8. Power characteristic curve of the PV power generation

Table 3. Work mode at different times

\begin{tabular}{c|c|c||c|c|c}
\hline Time & Summer & Winter & Time & Summer & Winter \\
\hline 1 & M3 & M3 & 13 & M1 & M1 \\
2 & M3 & M3 & 14 & M1 & M1 \\
3 & M3 & M3 & 15 & M1 & M1 \\
4 & M3 & M3 & 16 & M1 & M2 \\
5 & M3 & M3 & 17 & M2 & M2 \\
6 & M3 & M4 & 18 & M2 & M4 \\
7 & M2 & M4 & 19 & M2 & M4 \\
8 & M2 & M4 & 20 & M4 & M4 \\
9 & M2 & M2 & 21 & M4 & M4 \\
10 & M2 & M2 & 22 & M4 & M4 \\
11 & M1 & M1 & 23 & M4 & M3 \\
12 & M1 & M1 & 24 & M3 & M3 \\
\hline
\end{tabular}

The actual power characteristic curves of the battery in summer and winter are shown in Fig. 9 (the discharge power of the battery is positive, and the charging power is negative). The active power characteristics of the $0.4 \mathrm{kV}$ power grid before and after grid connection in summer and winter are shown in Fig. 10. The power factors of the $0.4 \mathrm{kV}$ power grid before and after grid connection in summer and winter are compared in Figure 11.

According to Figs. 10 and 11, after the microgrid is connected to the $0.4 \mathrm{kV}$ distribution line, the active power at the head end of the distribution line is smoothed, and the power factor at the head end of the distribution line is controlled between 0.97 and 1.0.

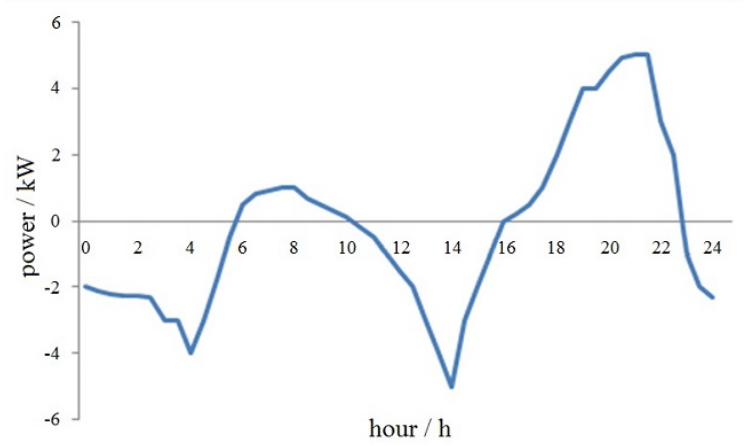

(a) Characteristic curve of battery power in summer

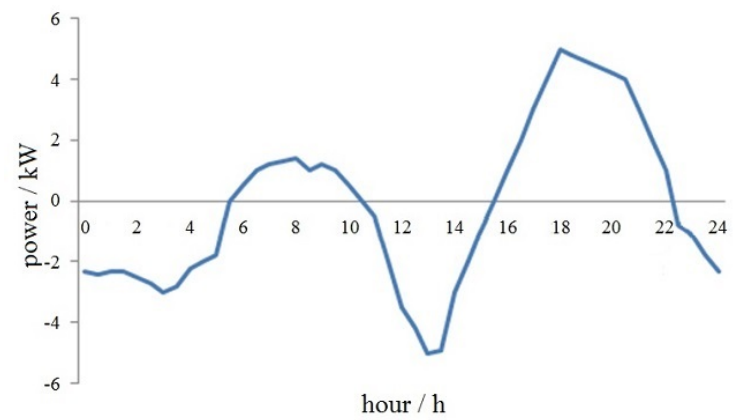

(b) Characteristic curve of battery power in winter

Fig. 9. Characteristic curve of the battery power

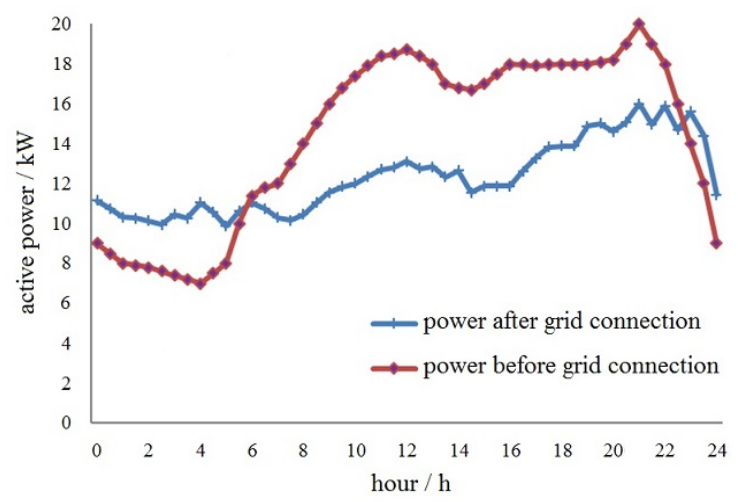

(a) Comparison of the active power characteristics before and after grid connection in summer

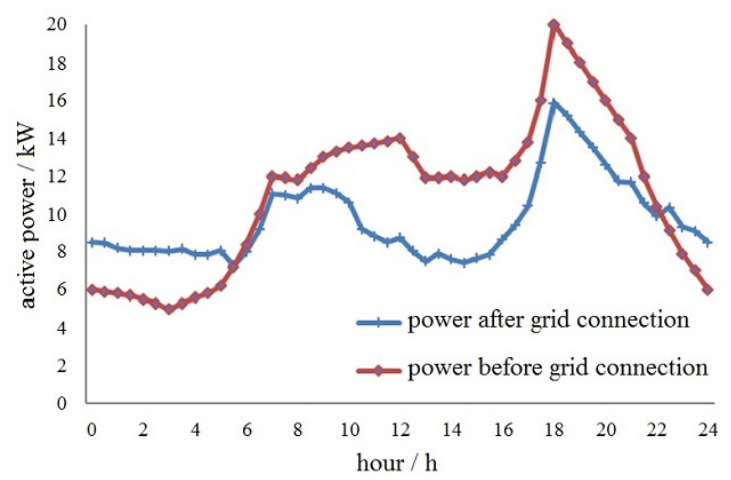

(b) Comparison of active power characteristics before and after grid connection in winter

Fig. 10. Comparison of active power characteristics before and after grid-connection

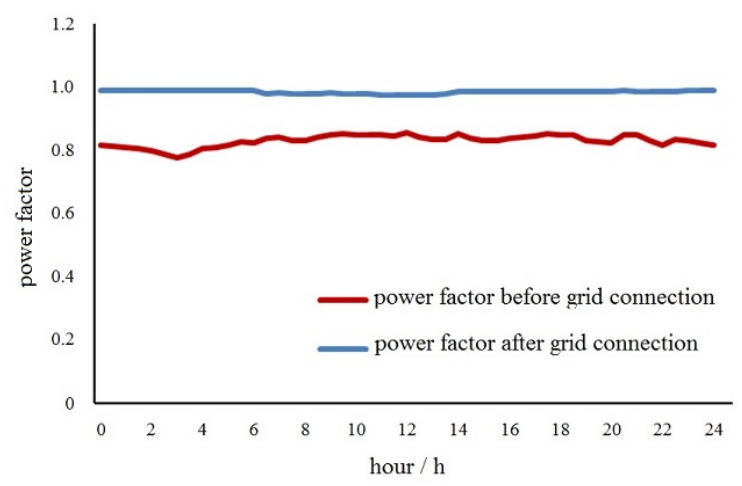

(a) Comparison of power factors before and after grid connection in

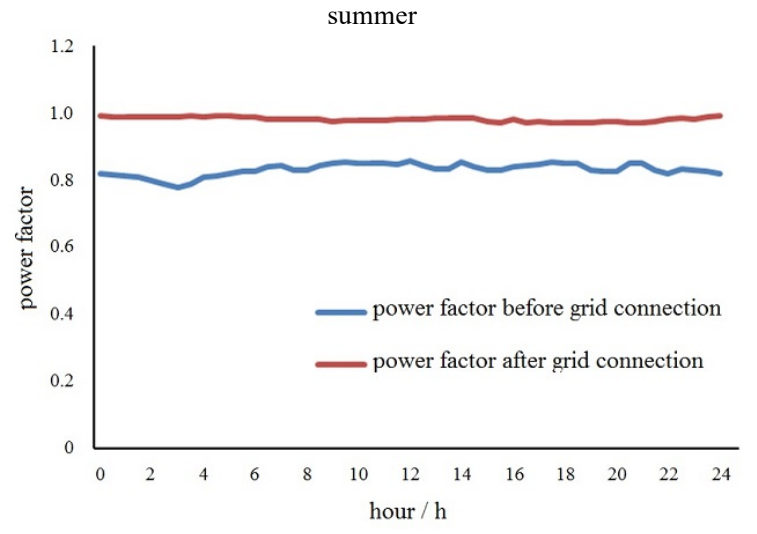

(b) Comparison of power factors before and after grid connection in winter

Fig.11. Comparison of power factor before and after grid-connection 


\section{Conclusions}

To optimize the power of grid-connected microgrid and maximize the utilization rate of renewable energy, this study controlled the active and reactive power of microgrid separately based on the organic whole of grid-connected microgrid and distribution network. By establishing mathematical model and membership function, the design method, work mode, and control strategy of PV and energy storage microgrid were investigated. The following conclusions could be drawn:

1) Considering the maximization of resource utilization and the complementarity of energy, this study designed a grid-connected PV and energy storage microgrid system. The active micro source is PV cell and energy storage cell, and the reactive micro source is $\mathrm{SVG}$.

2) Aiming at the grid-connected PV and energy storage microgrid system, this study analyzed the characteristics of PV power generation system and battery ESS from the perspective of power optimization. Considering the load operation of the system, a method that determines the capacity of micro source was proposed, expecting to optimize the system power.

3) The mathematical model for coordination control of microgrid system was proposed, and the work mode of active micro source was given. The work mode of active micro-source in microgrid was determined according to fuzzy control strategy. The reactive micro-source outputs reactive power in each period according to the reactive power optimization. Based on the balance of active power and reactive power in microgrid, the active power at the head end of the $0.4 \mathrm{kV}$ distribution line is smoothed, and the power factor of the $0.4 \mathrm{kV}$ distribution line is between 0.97 and 1.

In the microgrid design, this study combined the optimization of power and the maximization of utilization rate of renewable energy. The work mode and control strategy of microgrid were explored by establishing the mathematical model for determining microgrid capacity and coordination control, which has certain reference significance for microgrid design. Wind energy was not considered in the study of structural design of microgrid. In the future study, wind power generation will be introduced into microgrid, and the work mode and control strategy will be adjusted further to realize wide application of microgrid.

\section{Acknowledgements}

This work was supported in part by the Science Research Project of Hebei Higher Education (Nos. ZD2017036 and QN2016063) and Technology Foundation of Hebei Agricultural University (Nos. LG201601, LG201602, LG201605).

This is an Open Access article distributed under the terms of the Creative Commons Attribution License.

\section{References}

1. Zhang, G., Tang, X., Qi, Z., “Application of Hybrid Energy Storage System of Super-capacitors and Batteries in a Microgrid". Automation of Electric Power Systems, 34(12), 2010, pp.85-89.

2. Ehsan, A., Yang, Q., "Optimal integration and planning of renewable distributed generation in the power distribution networks: A review of analytical techniques". Applied Energy, 210, 2018, pp.44-59.

3. Tian, D., Chen, Z., "Subregional optimization of wind-solar microgrid composite energy storage system". Transactions of the Chinese Society of Agricultural Engineering, 35(21), 2019, pp.196201.

4. Pegueroles-Queralt, J., Bianchi, F. D., Gomis-Bellmunt, O., "A Power Smoothing System Based on Supercapacitors for Renewable Distributed Generation". IEEE Transactions on Industrial Electronics, 62(1), 2015, pp.343-350.

5. Yang, Y., Li, H., Aichhorn, A., Zheng, J., Greenleaf, M., "Sizing Strategy of Distributed Battery Storage System With High Penetration of Photovoltaic for Voltage Regulation and Peak Load Shaving”. IEEE Transactions on Smart Grid, 5(2), 2014, pp.982-991.

6. Dkhili, N., Eynard, J., Thil, S., Grieu, S., "A survey of modelling and smart management tools for power grids with prolific distributed generation". Sustainable Energy, Grids and Networks, 21, 2020, pp.121.

7. Yang, X., Su, J., Lü, Z., Liu, H., Li, R., “Overview on Micro-grid Technology". Proceedings of the Chinese Society of Electrical Engineering, 34(1), 2014, pp.57-70.

8. Zhang, Y., Ren, S., Yang, X., Bao, K., Xie, L., Qi, J., "Optimal configuration considering price-based demand response for standalone microgrid". Electric Power Automation Equipment, 37(7), 2017, pp.55-62.

9. Ma, Y., Yang, P., Wang, Y., Zhao, Z., "Typical Characteristics and Key Technologies of Microgrid". Automation of Electric Power Systems, 39(8), 2015, pp.168-175.

10. Shan, M., Li, C., Liang, T., Mao, W., "A Real-Time Optimal Control Strategy for Battery Energy Storage System to Smooth Active Output Fluctuation of Renewable Energy Sources". Power System Technology, 38(2), 2014, pp.469-477.

11. Liu, Z., Hu, Y., Chen, J., Yu, N., “A planning and design method for microgrid based on two-stage optimization". Power System Protection and Control, 43(8), 2015, pp.124-133.
12. Dou, X., Yuan, J., Wu, Z., Ni, Y., Fan, C., Xiao, Y., "Improved configuration optimization of $\mathrm{PV}$-wind-storage capacities for gridconnected microgrid". Electric Power Automation Equipment, 36(3), 2016, pp.26-32.

13. Lu, X., Guo, Q., Dong H., "Multi Objective Optimization of Hybrid Energy Storage Micro Grid Based on CMOPSO Algorithm". Acta Energiae Solaris Sinica, 38(1), 2017, pp.279-286.

14. Mansour-lakouraj, M., Shahabi, M., "Comprehensive analysis of risk-based energy management for dependent micro-grid under normal and emergency operations". Energy, 171, 2019, pp.928-943.

15. Elmouatamid, A., Ouladsine, R., Bakhouya, M., El K. N., ZineDine, K., Khaidar, M., "A control strategy based on power forecasting for micro-grid systems". In: 5th IEEE International Smart Cities Conference, Casablanca, Morocco: IEEE, 2019, pp.735-740.

16. Nassourou, M., Blesa, J., Puig, V., "Optimal energy dispatch in a smart micro-grid system using economic model predictive control". Journal of Systems and Control Engineering, 234(1), 2020, pp.96106.

17. Ko, H., Jang, M., Ryu, K., Kim, D., Kim, B., "Supervisory Power Quality Control Scheme for a Grid-Off Microgrid". IEEE Transactions on Sustainable Energy, 9(3), 2018, pp.1003-1010.

18. Sachs, J., Sawodny, O., "Multi-objective three stage design optimization for island microgrids". Applied Energy, 165, 2016, pp.789-800.

19. Omran, W. A., Kazerani, M., Salama, M. M. A, "Investigation of methods for reduction of power fluctuations generated from large grid-connected photovoltaic systems". IEEE Transactions on Energy Conversion, 26(1), 2011, pp.318-327.

20. Pappu, V. A. K., Chowdhury B., Bhatt R., "Implementing frequency regulation capability in a solar photovoltaic power plant". In: North American Power Symposium(NAPS), Arlington, USA: IEEE, 2010, pp.1-6.

21. Nanou, S. I., Papakonstantinou, A. G., Papathanassiou, S. A., "A generic model of two-stage grid-connected PV systems with primary frequency response and inertia emulation". Electric Power Systems Research, 127, 2015, pp.186-196. 
22. Wu, X., Wang, X., Wang, J., Bie, Z., "Economic generation scheduling of a microgrid using mixed integer programming". Proceedings of the Chinese Society of Electrical Engineering, 33(28), 2013, pp.1-8.

23. Guo, S.,Yuan, Y., Zhang, X., Bao, W. Liu, C., Cao, Y., Wang, H., "Energy management strategy of isolated microgrid based on multitime scale coordinated control". Transactions of China Electrotechnical Society, 29(2), 2014, pp.122-129.

24. Ding, M., Wang, B., Zhao, B., Chen, Z., "Configuration optimization of capacity of standalone PV-wind-diesel-battery hybrid microgrid”. Power System Technology, 37(3), 2013, pp.575-581.
25. Saif, A., Elrab, K. G., Zeineldin, H.H., Kennedy, S., Kirtley, J.L., "Multi-objective capacity planning of a PV-wind-diesel-battery hybrid power system". In IEEE International Energy Conference and Exhibition, Manama, Bahrain: IEEE, 2010, pp.217-222.

26. Huang, W., Tai, N., Fan, C., Lan, S., Tang, Y., Zhong, Y., "Study on structure characteristics and designing of microgrid". Power System Protection and Control, 40(18), 2012, pp.149-155.

27. Sun, H., Yao, P., Zhang, L., Zhang, J., Wang, L., "Bi-level Microgrid Optimal Dispatching Model Considering Active-reactive Power Coordinated Control”. High Voltage Engineering, 41(10), 2015, pp.3249-3255.

28. Su, J., Yu S., Zhao, W., Wu, M., Shen, Y., He H., "Investigation on engineering analytical model of silicon solar cells". Acta Energiae Solaris Sinica, 22(4), 2001, pp.409-412. 